\title{
2006-2654: EXPERIENTIAL LEARNING FOR INDUSTRIAL ENGINEERING CURRICULUM
}

\section{Sandra Furterer, University of Central Florida}

Sandra L. Furterer, Ph.D. is the Assistant Department Chair in the Industrial Engineering and Management Systems department in the College of Engineering and Computer Science at the University of Central Florida. Dr. Furterer's research and teaching interests are change management related to application of Lean Enterprise and Six Sigma, as well as engineering education.

\section{Jessica Jenness, University of Central Florida}

Jessica Jenness is an IEMS Masters student in Quality Engineering at the University of Central Florida. She has a Bachelor's of Science in Statistics from UCF. She is a Six Sigma Green Belt and a Graduate Research Assistant on the NSF grant to Reengineer the Undergraduate IE Curriculum.

\section{Jessica Steinberg, University of Central Florida}

Jessica Steinberg is an undergraduate IE student. She has worked as an intern for Lockheed Martin in Orlando, and as is currently an Undergraduate Research Assistant on the NSF grant to Reengineer the Undergraduate IE Curriculum.

\section{Lesia Crumpton-Young, University of Central Florida}

Lesia Crumpton-Young, Ph.D. is a Professor in the Industrial Engineering and Management Systems Department at the University of Central Florida. Her research interests are Ergonomics and Human Factors Engineering.

\section{Kent Williams, University of Central Florida}

Kent Williams, Ph.D., is an Associate Professor in the Industrial Engineering and Management Systems Department at the University of Central Florida. His research interests are Simulation and Training Systems Design and Development, and Cognitive Science.

\section{Luis Rabelo, University of Central Florida}

Luis Rabelo, Ph.D. is an Associate Professor in the Industrial Engineering and Management Systems Department at the University of Central Florida. His research interests are Engineering Management and Information Technology. 


\title{
Experiential Learning Opportunities Incorporated Into an Undergraduate IE Curriculum
}

\author{
Sandra Furterer, Ph.D., Jessica Jenness, Jessica Steinberg \\ Lesia Crumpton-Young, Ph.D., Kent Williams, Ph.D, Luis Rabelo, Ph.D. \\ University of Central Florida \\ 4000 Central Florida Blvd. \\ P.O. Box 162993 \\ Orlando, FL 32816-2993 \\ furterer@mail.ucf.edu
}

\begin{abstract}
The Department of Industrial Engineering and Management Systems with its Industrial Advisory board has embarked upon a multi-year effort to reengineer the undergraduate Industrial Engineering program. With the onset of more service industries and Information Technology firms, Industrial Engineering programs need to revise their curriculum to educate and prepare students to meet the expected workforce demands resulting from the shift of traditional manufacturing industries to non-traditional industrial sectors, and to incorporate additional emerging topics in the field. A critical part of this research project was to obtain the voice of the customers, industry and academia, that employ and receive our graduates once they successfully complete our undergraduate IE curriculum. The customers, through a series of surveys applied within a multi-round Delphi study, defined the desired characteristics that the graduates should have when they graduate, as well as emerging topics that should be incorporated into the curriculum. Important desired characteristics included adaptable problem solving skills, creative and critical thinking, teamwork skills, decision making skills, project management and leadership awareness. One important way to help our undergraduates attain these desired characteristics is through incorporating experiential learning opportunities into the curriculum. This paper describes our approach for incorporating experiential learning opportunities into the undergrad IE curriculum. It discusses the courses, timing of the experiences, and the components of the experiences that provide application of the course materials in project-based problem solving that enhance the students' critical thinking and adaptive problem solving skills.
\end{abstract}

\section{Introduction:}

The Industrial Engineering and Management Systems (IEMS) department in the College of Engineering and Computer Science at the University of Central Florida has incorporated several experiential learning opportunities into their curriculum. The goal of incorporating experiential learning opportunities is to provide real-world experience, projects, cases and applications to IEMS students prior to their obtaining their degrees. This will help to smooth the students' transition to career positions after graduation.

Opportunities currently in place include senior design projects, Six Sigma projects, internships, 
co-ops, a mentoring program including interaction with student chapters of professional organizations, and undergraduate research projects. We are currently developing other experiential opportunities to further incorporate real-world experiences into the curriculum including developing remote learning laboratories in partnering with industry organizations. A senior design course project is a standard requirement for industrial engineering undergraduates. Students must enroll in a senior design course during each semester of their senior year. The course prepares students for work in the industry by assigning them to work on a companysponsored project. Students must utilize academic tools learned throughout their college career to meet the demands of the project and present results to the company. The Total Quality Improvement course, ESI 5227, is a mixed graduate and undergraduate course that focuses on the development of tools for the management and improvement of quality in different organizations. ${ }^{[1]}$ Essential concepts, practices, and methods of modern quality improvement tools are discussed, along with the Six Sigma DMAIC (Define, Measure, Analyze, Improve, and Control) problem solving approach, and critical success factors to team building and teamwork. Six Sigma team projects are performed that apply the class lecture material to "real world" organizations. Students may also seek credit for experiential learning through internships. Internship opportunities are posted on the IEMS website and also advertised through career fairs sponsored by student chapters of American Society for Quality (ASQ) and Institute of Industrial Engineers (IIE). Co-ops positions are also available through the Career Services \& Experiential Learning Center on campus. The Lockheed Martin Work Experience Program employs several students every semester. IEMS is currently piloting a mentoring program with the local ASQ Orlando Section 1509. A plan is in place to implement similar mentoring programs with IIE and other professional organizations. Remote Learning Labs bring industry to the classroom on a more regular basis. All experiential learning opportunities are helping to build stronger industry partnerships with the university. This paper describes our approach for incorporating experiential learning opportunities into the undergrad IE curriculum. It discusses the courses, timing of the experiences, and the components of the experiences that provide application of the course materials in project-based problem solving that enhance the students' critical thinking and adaptive problem solving skills.

\section{Senior Design Course:}

The Department of Industrial Engineering and Management Systems at the University of Central Florida offer their senior undergraduate students a unique capstone design educational experience. Teams composed of 3-5 senior Industrial Engineering students develop and implement a plan to improve operations within a segment of a local industrial partner. This 36 week activity, beginning in the fall semester and ending in the following spring semester, is closely directed by a mentoring team composed of UCF faculty members and experienced professionals from the partner company.

Project teams are comprised of students in their final year of undergraduate study in Industrial Engineering. Students are typically highly motivated by the opportunity to practice their professional skills and to add a high-quality work experience to their resume. Students receive a mixture of academic lectures and professional mentoring as they identify, confront and solve real-world problems.

The primary objective of the course is to facilitate the transition from academia to industry. ${ }^{[1]}$ 
Students, working together in multi-disciplinary teams, will be able to integrate and apply their engineering and business skills to solve open-ended, unstructured, real-world problems.

Engineering students will be able to use the engineering design process to provide structure for engineering problem solving. Students will be able to exercise consulting skills, team building, leadership techniques, effective communication, problem solving ability, and creativity to solve client problems. IEMS utilizes the senior design course as a critical part of assessing the undergrad program.

Student teams are formed in advance of final project selection. Each team is composed of three to five IE students. Team formation is student driven, however, there is a need for balance to ensure that each team has similar capabilities. To assist in this process, students share professional resumes and project preferences. After team formation, team members may be traded with consensus of both teams and faculty approval. Prospective industry partners create project summaries for students to review. Companies visit UCF and present a brief overview of prospective projects. Students identify their project preference which assists in team formation.

There are four deliverables associated with the senior design project. The proposal is developed early in the first semester and serves as the contract between the team, the client, and the instructor. The baseline summary outlines findings and suggests opportunities for improvement and is completed at the end of Fall Semester. The alternative review, due near the middle of the spring semester, describes viable alternatives and discusses likely benefits/costs. The final report summarizes recommendations, justification and implementation results, if applicable.

\section{Total Quality Improvement Course:}

Total Quality Improvement, ESI 5227, is course currently offered to a mix of graduate and undergraduate students and provides a broad exposure to topics in quality improvement. ${ }^{[2]}$ The course was first implemented in 2004 as a graduate-level course. In 2005, it was open to all levels and IEMS is now developing a similar course strictly for undergraduates. It provides learning of the Six Sigma DMAIC problem solving approach and allows the students to perform just-in-time experiential learning opportunities encompassed in a Six Sigma project. The course runs for the 16-week semester and is intended to focus on the development of tools for the management and improvement of quality in community-based organizations. Essential concepts, practices, and methods of modern quality improvement tools are discussed, along with the Six Sigma DMAIC problem solving approach, and critical success factors to team building and teamwork. The Six Sigma team projects are performed by the students applying the DMAIC problem solving approach and appropriate quality tools to help a community-based organization understand and improve their processes and use of technology. The tools are applied within the phases of the DMAIC problem solving methodology, as they are learned in the lecture portion of the course.

The course consists of a lecture component that uses PowerPoint presentations to teach the students the principles and tools of Six Sigma and the DMAIC problem-solving approach. Case study examples of "real world" application of Six Sigma tools are presented to the students to enhance their understanding of the tools. The students select teams of five to seven students that apply the DMAIC and Six Sigma tools in a community organization throughout the semester. The students perform the Define, Measure, and Analyze phases of the DMAIC problem solving 
approach and suggest process improvement and control recommendations that allow the project sponsors to Implement the recommendations and Control mechanisms. The course instructor, the principle author of this paper, serves as the Master Black Belt that provides mentoring to all of the teams. Professionals from the local ASQ Orlando Section 1509 perform Six Sigma Black Belt coaching and knowledge transfer for each of the student teams. A certified Six Sigma Green Belt leads or mentors each team.

The weekly class is composed of two hours of lecture and one hour of in-class team-based problem solving and team-building activities. Each student spends about 8 to 10 hours per week outside of class on the Six Sigma project activities, for a total resource and mentor effort of approximately 5200 hours across the 16-week semester. The students complete a team assessment to extract lessons learned as well as a 360 degree assessment across the teams to understand the level of effort and commitment of each student on the Six Sigma project. The students share knowledge across the teams by uploading their presentations and reports to a shared website. The project champions also complete an assessment of the value provided by each team to the champion's organization.

The Total Quality Improvement course was taught in the fashion described above for the first time in the Fall 2004 semester at UCF. Thirty-one students participated in the course and related Six Sigma projects. In Fall 2005, thirty graduate students and twenty undergraduates were enrolled and completed eight Six Sigma projects. Five to seven students per team helped organizations improve their processes and how they used technology. Five of the eight teams were organizations within the university and the other three were a high school, a children service center, and a financial services organization who agreed to share the lessons learned from the project to enhance future students' learning.

\section{Internships:}

Students may also seek credit for experiential learning through internships. According to a 2001 survey by the National Association of Colleges and Employers, more than $93 \%$ of respondents said that their institutions offered internship programs. In the survey, employers indicated that they later hired those interns for full-time jobs. ${ }^{[3]}$

The Career Services \& Experiential Learning Center (CELC) maintains a large database at UCF called KnightLink. Students may create an account containing information about their academic and professional background, work preferences, and upload their resume. Employers can access student resumes, with permission, to search for desirable internship and co-op candidates. In the same right, students have access to the employer database to search for internship and co-op opportunities. CELC also holds multi-disciplinary internship fairs. Students may access the CELC website to see a list of employers who have registered to attend.

IE internship opportunities are also posted on the IEMS website and also advertised through career fairs sponsored by student chapters of ASQ and IIE. IEMS is currently developing a more local database similar to CELC's KnightLink in which student profiles and resumes are managed along with employer information.

To obtain credit, students seek out a faculty advisor to obtain approval. Students then receive authorization to register for an independent study/internship. Usually, a mid-term and post-term 
report must be submitted along with a final presentation.

\section{Co-ops:}

The Lockheed Martin Work Experience Program provides students an opportunity to gain professional work experience related to their academic discipline while maintaining full-time university enrollment. The program is maintained through CELC where there is a liaison that maintains an office in both locations, at CELC and at Lockheed Martin. Students must have an established UCF GPA of at least 3.0 in order to apply and also maintain that average while working. Students work between 12 and 20 hours per week during the semester. Graduate students and seniors in their last semester are permitted to work up to 30 hours per week.

\section{Mentoring Programs:}

IEMS is currently piloting a mentoring program with the local ASQ Orlando Section 1509 . The goal is to define and implement a self sustaining mentor program that matches ASQ students with ASQ members. A plan is in place to implement similar mentoring programs with IIE and other professional organizations. The professional and personal growth potential is unlimited.

Students enroll via web form between August 1 and September 30 for a two-semester program ending April 30. A Mentor Committee is formed by a UCF IE Representative, a UCF ASQ Student Chapter Leadership Committee Member, and an ASQ Section 1509 Leadership Committee Member to review potential applicants. The student is then interviewed by the ASQ Section 1509 Leadership Committee Member. A Successful Relationship Goal is completed by the student via web form. The Leadership Committee Member reviews the web form and interview data to create a protégé profile. The Leadership Committee Member identifies up to three potential mentors. The Mentor Committee assesses member profiles and selects the best matched mentor.

The mentoring process begins with a simple introduction. Then, the process becomes protégédriven. The protégé completes monthly reports via web form. The Mentor Committee reviews the reports prior to the next checkpoint and responds as appropriate up to and including contact with the mentor. In April, the protégé submits a final report detailing lessons learned via web form. The Mentor Committee rates program results base on a scale of 1 to $4,1=$ did not complete, 2 = completed, $3=$ exceeded, $4=$ outstanding. The Mentor Committee reports results to mentor, protégé, and ASQ Section 1509 Historian.

\section{Research Projects:}

Undergraduate research can, among other things, attract students to graduate school through increasing their enthusiasm for research; encourage undergraduates to view education s more relevant for their future lives; and help minority or non-traditional students to identify more closely with the institution. ${ }^{[3]}$

While many faculty members believe that only graduate students can engage in research that is meaningful to them, a program at Maryland for first-year chemistry students, for example, provides them the opportunity to solidify their commitment to the discipline and become valuable research assistants while still undergraduates. Some of these same students have accomplished college honors theses, advanced research projects, and enrollments in masters and 
doctoral degree programs. ${ }^{[3]}$

IEMS faculty, undergraduate and graduate students team on research projects. The department promotes and the faculty actively pursues interested undergraduate students to add them to their research projects.

\section{Remote Learning Laboratories:}

The idea of remote learning laboratories is to incorporate live industry case studies into the classroom. Adaptive problem solving skills can be effectively fostered by applying real world case examples, data, and challenges to relevant techniques learned in the classroom. Remote Learning Labs also build strong industry partnerships by partnering with companies and organizations that can provide examples, cases and data.

Areas of application include engineering management, operations research, cost engineering, human engineering, manufacturing systems, quality systems, and simulation.

\section{Summary and Conclusions:}

There are several experiential learning opportunities available to help students better prepare for work in the engineering industry while building strong industry partnerships with the university. The senior design course available to graduating seniors provides an excellent means for students to exercise skills learned in academia and apply them in creative ways. The project demands teamwork, communication, leadership, and problem-solving skills. The Total Quality Improvement course provides a valuable opportunity for graduate students to learn and apply Six Sigma tools and the DMAIC problem solving approach. More traditional experiential learning opportunities are still in place, but with higher technology facilitating ease of use. CSEL's KnightLink system is available on the internet, making the database easily accessible to students and employers. Industry has become increasingly more involved with internships and co-ops as evidenced through participation in internship fairs and the creation of programs like the Lockheed Martin Work Experience Program. Members of professional organizations are serving as mentors, building a stronger connection with student organizations. Undergraduate research is being explored bringing benefits such as an early solidification in the field, ideas for college honors theses, and enrollment in masters and doctoral programs. Industry connections are brought to the classroom regularly through remote learning laboratories. This paper described these various experiential learning opportunities and how they educate students about essential soft topics including adaptable problem solving skills, creative and critical thinking, teamwork skills, decision making skills, project management and leadership awareness. These desired characteristics are crucial for future of the engineering industry.

\section{References:}

[1] Mullens, M.A., Industrial Engineering Senior Design Course, EIN4891C, Course Syllabus, University of Central Florida, 2005.

[2] Furterer, S.L., Total Quality Improvement, ESI 5227, Course Syllabus, University of Central Florida, 2005. 
[3] Steffes, J.S. Creating Powerful Learning Environments Beyond the Classroom. Change v. 36 no. 3 (May/June 2004) p. 46-50

http://iems.ucf.edu/ver40/resources/Seniordesign.htm

\section{Biographical Information:}

\section{Sandra L. Furterer, Ph.D.}

Sandra L. Furterer, Ph.D. is the Assistant Department Chair in the Industrial Engineering and Management Systems department in the College of Engineering and Computer Science at the University of Central Florida. Dr. Furterer's research and teaching interests are change management related to application of Lean Enterprise and Six Sigma, as well as engineering education.

\section{Jessica Jenness, IEMS Masters student}

Jessica Jenness is an IEMS Masters student in Quality Engineering at the University of Central Florida. She has a Bachelor's of Science in Statistics from UCF. She is a Six Sigma Green Belt and a Graduate Research Assistant on the NSF grant to Reengineer the Undergraduate IE Curriculum.

\section{Jessica Steinberg, IEMS Undergraduate student}

Jessica Steinberg is an undergraduate IE student. She has worked as an intern for Lockheed Martin in Orlando, and as is currently an Undergraduate Research Assistant on the NSF grant to Reengineer the Undergraduate IE Curriculum.

\section{Lesia Crumpton-Young, Ph.D.}

Lesia Crumpton-Young is a Professor in the Industrial Engineering and Management Systems Department at the University of Central Florida. Her research interests are Ergonomics and Human Factors Engineering.

\section{Kent Williams, Ph.D,}

Kent Williams is an Associate Professor in the Industrial Engineering and Management Systems Department at the University of Central Florida. His research interests are Simulation and Training Systems Design and Development, and Cognitive Science.

\section{Luis Rabelo, Ph.D.}

Luis Rabelo is an Associate Professor in the Industrial Engineering and Management Systems Department at the University of Central Florida. His research interests are Engineering Management and Information Technology. 